\title{
Effectiveness of Mobile Positive Health Dignity and Prevention Messages on the Attitude of HIV Positive Young Adults receiving Antiretroviral Treatment in Yola, Nigeria
}

\author{
S O Adeyemi ${ }^{1 *}$, K U Suru ${ }^{2}$, J E Chiegil ${ }^{1}$, O F Martins ${ }^{2}$ \\ ${ }^{1}$ Texila American University, Guyan ${ }^{1}$ \\ ${ }^{2}$ Department of Public Health, Federal Medical Centre Yola, Adamawa State, Nigeria
}

\begin{abstract}
Positive Health, Dignity, and Prevention (PHDP) is a term for HIV prevention interventions with people living with HIV. Negative attitudes toward HIV medications may restrict utilization of antiretroviral therapy. Young adults with HIV are less likely to be adherent to ART. We investigated the effectiveness of mobile Positive Health Dignity and Prevention messages on the attitudes of HIV positive young adults (18-30 years) enrolled in care in the ART comprehensive sites in Yola, Nigeria. This was a randomized controlled trials study consisting of 371 young people living with HIV enrolled into antiretroviral treatment (ART) in 6 comprehensive sites in Yola. In addition to the routine care received during ART refill, the intervention group (186) received a total of 48 daily mobile PHDP text messages for the duration of 48 days while the control group (185) also received 48 daily mobile personal hygiene text messages for the duration of 48 days as placebo. A pre-validated structured questionnaire was used for data collected. Data was collected at baseline, two, four and six months respectively. Data was analyzed using SPSS version 24. Test of significance was at a level 0.05. Mean $\pm S D$ attitude scores at baseline and 6-month follow-up were $38.46 \pm 4.657$ and $40.04 \pm 4.943$ respectively in the intervention group. The control group had mean $\pm S D$ attitude score of $35.92 \pm 4.677$ at baseline and 35.88 \pm 4.704 at 6-month follow-up period. A repeated measures ANOVA with a GreenhouseGeisser correction showed a significant increase in the mean attitude scores from based line to 6 months follow up differed statistically significantly between the time points $\left(F_{(1.162,210.381)}=155.479 p<0.001\right)$ in intervention group. The repeated ANOVA measures for the control group from baseline to 6 months follow up did not show a statistical difference between the time points $\left(F_{(1.906,343.144)}=0.950 p=0.384\right)$, and indicate no statistically significance was seen. Mobile positive health dignity and prevention text messages were effective in improving the attitude of young PLWHA towards ART in Nigeria.
\end{abstract}

Keywords: Attitudes, ART, HIV positive young adults, Mobile Positive Health Dignity Preventive message, Nigeria.

\section{Introduction}

HIV is a major health challenge and one of the leading causes of death from infectious disease worldwide. It was estimated in 2016 that about 36.7 million people were living with HIV with about 1.8 million people became newly infected with HIV, an estimate of 1 million died from AIDS-related causes in 2016, and about 19.5 million people were accessing antiretroviral therapy in the same year [1]. An estimate of 4 million people living with HIV globally are young people between the age of 15-24 years [2]. Sub-Saharan Africa remained the most hit region with about 25.6 million people living with HIV, and two-thirds of new HIV infections globally occurred in this region. Young people make up a portion of the population that is specifically vulnerable to HIV [3]. Nigeria has the second highest HIV epidemic globally next to South Africa.

Adamawa state in the North-Eastern region of Nigeria has an estimated population of 4 million [4]. The state had witnessed fluctuations in the pattern of the ANC HIV sentinel prevalence between 1999 and 2010 showing prevalence of $4.5 \%$ in 2001 to $7.5 \%$ in 2003 , declining to $4.2 \%$ in 2005 and rising to $6.8 \%$ in 2008 but declined again to $3.8 \%$ in 2010 [4]. In 2015, prevalence of HIV in Adamawa State was $2.5 \%$ with an estimated 50,433 adult People Living with HIV (15 years +), adult ART achievement of 25,341 
(50.2\%). These PLWHA enrolled in care received Positive Health Dignity and Prevention intervention as part of the standard ART services.

Positive Health, Dignity, and Prevention (PHDP) is a term for HIV prevention interventions with people living with HIV. PHDP is alternatively known as positive prevention, prevention with positives, prevention by positives, and prevention for positives. It involves supporting $\mathrm{HIV}$-positive people to learn and practice how to live healthily and minimize the risks of their spreading the virus to others [5]. PHDP is a relatively new area of focus for HIV prevention programmes. Historically, HIV prevention efforts have tended to focus on reducing HIV risk among HIVnegative people or those with unknown serostatus, while overlooking the precise role that HIV-positive people can play in prevention. Substantial gains in the treatment and care of people living with HIV (PLHIV) and attention to and funding of ARV treatment have resulted in larger numbers of people living longer with HIV. There is thus a growing acknowledgment of the urgent need to find effective ways to engage this population in HIV prevention efforts that are suitable to their needs [6]. Adding a focus on HIV prevention interventions with PLHIV may improve overall HIV prevention strategies [7]. There is the need to strengthen PHDP intervention among PLWHA who are on ART.

Adherence to ART is one of the major identified elements to improve the quality of life of People Living with HIV/AIDS (PLWHA), avoid re-infection, and prevent further spread of resistant strains. ART has transformed HIV infection into a treatable, chronic condition like hypertension. Non-adherence has been tagged as one of the main contributing factors in HIV treatment failure, which can lead to clinical progression of the disease [8]. Negative attitudes toward HIV medications may further fuel nonadherence to ART [9]. Young adults with HIV are less likely to be adherent to ART $[10,11,12$, $13,14]$. There is the need to strengthen the delivery of interventions that encourages positive attitude towards ART among young people living with HIV/AIDS. This study evaluates the effectiveness of mobile PHDP messages on the attitudes of HIV positive young adults (18-30 years) enrolled in care in the ART comprehensive sites in Yola, Nigeria.
Young people are the highest users of mobile phones worldwide. The gains of mobile phone usage in improving health interventions across high and low-income countries cannot be overemphasised. Mobile phone technology has advanced so greatly in recent years that phones can no longer be seen as simple mobile communication devices. Medical community has over the last decade embraced this technology and is realizing its potential in healthcare information delivery, real-time patient monitoring, research data collection and mobile telemedicine for the provision of expertise to remote locations. Improved ART clinic attendance in Uganda was demonstrated when participants were sent SMS or voice reminders [15]. Two studies conducted in Nigeria demonstrated that adherence counselling and text message reminders improved adherence among HIV patients [16, 17].

A Cochrane database system review on SMS interventions in Kenya show that weekly SMS messaging improved adult ART adherence compared to standard care at 48-52 weeks [18]. A systematic review of PMTCT interventions found that SMS reminders is convenience, cost effective and improved retention of motherinfant pairs at 18 months [19]. Another study carried out in Malaysia indicated that mobile phone reminders (SMS and telephone call reminders) and peer counselling are effective in enhancing adherence and treatment outcomes among HIV-positive patients on ART in Malaysia [20]. Mobile phone text message, or SMS, reminders to promote ART adherence is recommended in PEPFAR [21] and WHO guidelines [22]. However, its utilization is low in many resource limited countries, Nigeria inclusive.

Although several studies have been conducted on the use of mobile phones to improve the outcomes of HIV/AIDS interventions, there is no documented literature on the use of mobile phone to improve Positive Health Dignity and Prevention amongst young PLWHA in Nigeria, hence the decision to conduct this study.

\section{Methods}

\section{Study Design}

The study was conducted in six selected comprehensive ART treatment sites located in Adamawa State, Nigeria (Yola Specialist 
Hospital, Federal Medical Centre Yola, St Francis Hospital Jimeta, Adamawa Hospital Yola, Peace Hospital Yola, and Boshang Clinic Jimeta. It utilized a two-arm single blind Randomized Controlled Trial (RCT) to evaluate the effectiveness of mobile Positive Health Dignity and Prevention (PHDP) messages on the attitudes of HIV positive young adults (18-30 years) enrolled in care in six selected comprehensive ART sites in Yola, Nigeria. The study was conducted from November 2017 to September 2018.

The study comprised of all young HIV patients (male and female) within the age of 1830 years who were enrolled in care and are currently receiving ART based on the national protocol during the period prior to the commencement of the study at the six selected study locations. The criteria for the inclusion of participants into this study involved all HIVpositive patients who were currently active on ART treatment at the selected study locations during the period before the commencement of this study, who were able to read, write and comprehend English and Hausa, had valid and active telephone number, and fell within the age range of 18-30 years. Clients who did not meet the inclusion criteria, and all confirmed pregnant clients were excluded from the study.

Sample size was calculated for all outcome variables. The largest sample size was obtained for the outcome variable of knowledge of HIV/AIDS. A total of $371(10 \%$ attrition inclusive) participants for both the intervention group and the control group was calculated using the formula below [23]. The sample frame consisted of all HIV positive young adults age 1830 years enrolled in care who attended ART clinic refill during the time of enrolment of participants into the study in the six study locations. The enrolment of participants was done during clinic ART refill days and it's lasted for 4 weeks across the six study locations.

$$
n=\frac{\left\{Z_{1-\alpha} / 2 \sqrt{2 \bar{P}(1-\bar{P})}+Z_{1-\beta} \sqrt{\left(P_{1}\left(1-P_{1}\right)+P_{2}\left(1-P_{2}\right)\right.}{ }^{2}\right.}{\left(P_{1}-P_{2}\right)^{2}}
$$

Where: $\mathrm{P}_{1}=0.90$ (Desired level of HIV/AIDS knowledge); $\mathrm{P}_{2}=0.77$ [24] Baseline; $\overline{\mathrm{P}}_{=} \mathrm{P}_{1}+\mathrm{P}_{2} / 2=$ $0.90+\frac{0.77}{2}=\frac{1.67}{2}=0.835 ;$ and $\mathrm{z} 1_{-\alpha / 2}=1.96$ at $95 \% \mathrm{C}$

\section{Sampling}

Eligible clients were sampled using systematic random sampling from the six study locations. One of the research assistants was asked to choose a lucky number from number 1 to 4 and she chose number 4 . Every fourth (4th) young PLWHA age 18-30 years who came to the clinic for Antiretroviral drug refill that day was sampled for eligibility to participate in the study across the 6 study locations. The sampling lasted for 4 weeks across the study locations. A total of 492 young PLWHA were sampled from the sample frame and were assessed out of which 98 did not meet the inclusion criteria and 23 declined participation. The clients (371) who met the inclusion criteria were randomised into the intervention group (186) and control group (185). Colour-coded sticky notes were used to allocate participants to intervention and control group. A total of 371 colour coded sticky notes were placed in separate sealed opaque brown envelopes (186 yellow notes represented intervention group; 185 blue notes represented control group). This was shuffled in the box and re-shuffled after each client picked. Clients picked a single envelope one by one under the supervision of the trained research assistants. The research assistant opened the sealed envelope and used the colour code to know which group the client belonged and so determined who received the intervention and who did not base on their chosen colour. A single blinded technique was used with clients do not know the group they belong to. A total of 17 PLHWA aged 18-30 years were sampled from study location one, 26 from study location two, 89 from study location three, 26 from study location four, 161 from study location five and 58 from study location six.

\section{Intervention}

A total of 48 mobile PHDP text messages were developed as the intervention. The messages included chronic HIV care with ART and prevention and Integrated Management of Adolescent and Adult Illness [25]. A total of 48 personal hygiene messages were adapted as 
mobile text messages from hygiene practices for patients with HIV/AIDS [26] as placebo.

The content validity of the all the messages developed were done in two phases. The first phase involved sharing the messages with 3 professionals including 1 Public Health Physician and 2 HIV/AIDS specialists for their feedback and recommendations which the researcher inputted. The interventions were field tested in Specialist hospital Yola, one of the study locations, in the second phase of validation. A total of 30 young PLWHA age 1830 (15 males and 15 females) were selected during ART clinic refill day based on their ability to read in both English and Hausa. The researcher assessed their understanding of each message and modified the messages based on the feedback received. The text messages were sent through bulk SMS services provided by LOFTYSMS [27], SMS service delivery provider. The mobile number of all the participants, collected at the time of enrolment, were stored based on the two research groups.

In addition to the routine PHDP care received during ART refill, the intervention group received a total of 48 daily mobile PHDP text messages for the duration of 48 days, one text message per day. The control group also received additional 48 daily mobile personal hygiene text messages for the duration of 48 days, one text message per day, as placebo. All the text messages, both the PHDP and the personal hygiene messages, were translated from English to Hausa and translated back into English by a certified translator.

\section{Data Collection Instrument}

The study instrument was a self-administered questionnaire consisting of closed-ended questions that were constructed of questions derived from previously validated questionnaires that were administered as part of relevant previous studies $[28,29,30,31,32,33$, $34]$. In order to assess the content validity of the questionnaire, it was assessed by 3 professionals in the field of infectious diseases, with a specialty in HIV/AIDs. The questionnaire was pretested in the ART clinic of St Francis hospital and Specialist Hospital Yola to assess the reliability. It involved 30 (15 males and 15 females) young PLWHA within the age of 18-30 years, who would not be considered part of the study group at the time the study would be conducted.

The attitudes portion of the questionnaire consisted of 13 items that were measured on a four-point Likert-type scale ranging from strongly agree to strongly disagree. Maximum possible score for the attitude section was $13 \times 4=52$ [35]. The 13 items regarding attitudes contains set of questions covering general stigma towards HIV/AIDS; medicine and stigma towards HIV/AIDS; emotions and fears regarding HIV/AIDS; and HIV/AIDS-related medical protocol. The internal validity (alpha Cronbach) of the attitude was 0.8252 .

\section{Data Collection}

Data was collected at baseline, two, four and six months respectively.

\section{Data Analysis}

Data was analysed using Statistical Package for Social Sciences (SPSS) version 24.0. Percentage distributions of attitude towards ART were performed and tabulated. A 4point Likert scale was used, ranging from strongly disagree to strongly agree. A mark of 1 was awarded for strongly disagree, 2 for disagree, 3 for agree and 4 for strongly agree. Negatively asked questions were reversed coded. All scores were added to get the aggregate score. The descriptive statistics for the mean of attitude scores were tabulated. Baseline comparison of mean attitude scores of the intervention and control groups were obtained by independent $t$ test, and repeated measures ANOVA was used to evaluate the effectiveness of the PHDP Messages on attitude scores at 2, 4 and 6 months. A p-value $<0.05$ was considered as statistically significant.

\section{Ethics}

Ethical clearance was obtained from the Adamawa State Ministry of Health, Department of Research and Statistics ethical committee. Informed consent was obtained from each participant through a written and signed informed consent form before they were enrolled into the study. 


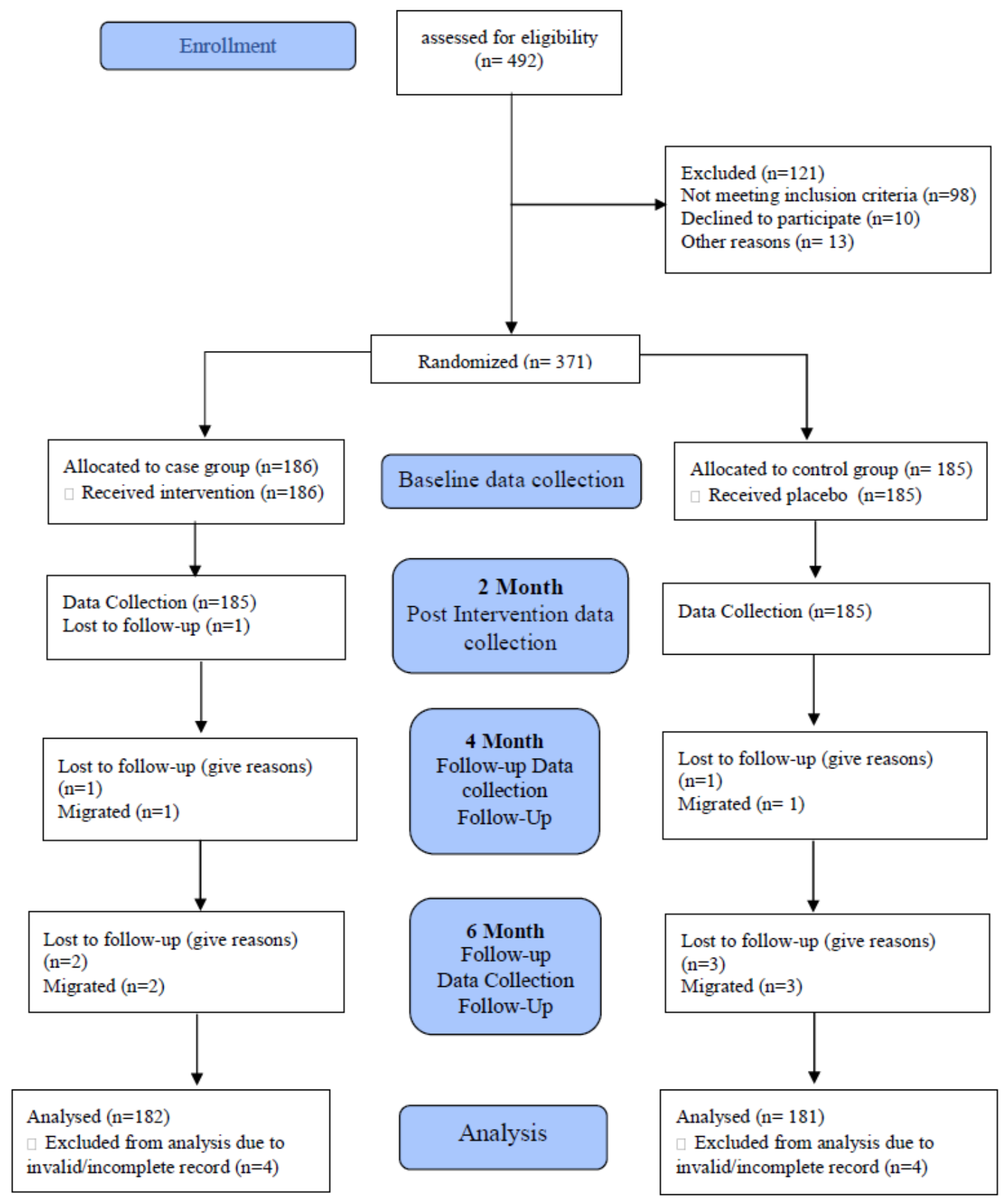

Figure 1. Activity Flow

\section{Results}

\section{Socio-demographic Characteristics of the Respondents}

Over half of the respondents $(57.5 \%$; 107) in the intervention group and about half of respondent $(50.3 \%)$ in the control group were between the ages 26 and 30 years. The mean \pm $\mathrm{SD}$ ages of the respondents in the intervention and control groups were $25.57 \pm 2.990$ years and $24.91 \pm 2.986$ years respectively. Majority of the HIV infected young adults in both intervention 
$(82.3 \%)$ and control (80.5\%) groups were females. The distribution of marital status showed that in the intervention group, over half of the young adults (55.9\%) were married and 19 participants had been divorced. In the control group, more participants were single $(55.1 \%)$ and $1.6 \%$ were widowed. About half of the participants $(49.5 \%$; 92) in the intervention group had a secondary level of education and $16.1 \%$ had no form of formal education. Only $25.9 \%$ had a higher/tertiary form of education in the control group, and $18.9 \%$ had no formal education. About a quarter of the young adults in the intervention group were housewives, $36.6 \%$ (68) were self-employed, while $16.1 \%$ were students. Almost half of the participants in the control group were self-employed and $14.6 \%$ (27) were students. No statistical differences were seen for age, sex, marital status, level of education and employment statuses between the intervention and control groups.

\section{Baseline Distribution of Respondents' Attitudinal Disposition towards Antiretroviral Medications}

The attitudinal disposition of the young people at baseline was measured with a 13-item scale. More of the young people in the intervention group $(60.2 \%)$ disagreed that they were worried about other people knowing their HIV status by noticing their medication intake; four people strongly agreed and 60 (32.2\%) agreed. In the control group, however, more people strongly agreed $(58 ; 31.4 \%)$ that they were worried and 24 people $(1.0 \%)$ strongly agreed. Almost two-thirds of the respondents in the intervention group $(64 \% ; 119)$ disagreed with the statement that inquired about their frustration of taking the medications because they had to plan their lives around it while $43.8 \%$ (81) of the young people in the control group felt same. Majority of the people in the intervention group (strongly agreed: $30.6 \%$; agreed; $59.1 \%$ ) agreed that their healthcare providers take their needs into account while about half had the same disposition in the control group (strongly agreed: 9.7\%; agreed; $43.8 \%$ ).

The proportion who agreed to have positive support from people who are aware of their status was high in the intervention group, but only a $40 \%$ agreed in the control group. About two-thirds $(67.2 \%)$ in the intervention group disagreed that they did not have the urge to have sex with strangers when they were drunk with alcohol, while only $36.8 \%$ had the same disposition in the control group.

\section{Comparison of Mean Baseline Attitude Scores between Intervention Group and Control Group}

The mean \pm SD baseline attitude score of the respondents in the intervention groups was $38.467 \pm 4.652$ and $35.929 \pm 4.677$ for the control group. The independent $t$ test result for equality of mean baseline HIV knowledge score between the intervention group and the control group was statistically significant $(\mathrm{p}=0.000)$. The result showed that both the intervention group and the control group had non-equal mean attitude scores at baseline. The intervention group has higher baseline mean attitude score than the control group. However, the Leven's test for equality of variance between the two groups was not statistically significant $(\mathrm{p}=0.267)$. This means that the variances are approximately equal. The result shows that the respondents in the two groups were drawn from the same sample population.

\section{Effectiveness of Mobile PHDP Intervention on the Attitudinal Disposition of Young People Living with HIV/AIDS}

A repeated measure ANOVA with a Greenhouse-Geisser correction determined that mean attitude score differed statistically significantly between the time points ( $\mathrm{F}_{(1.162}$, 210.381) $=155.479 \mathrm{p}<0.001)($ Table 1). Post hoc tests using the Bonferroni adjustment for multiple comparisons showed the mobile Positive Health Dignity and Preventive (PHDP) text messages elicited an increase in the level of attitude from baseline to 6 months follow-up period $\quad(38.46 \pm 4.657$ vs $40.04 \pm 4.943$ respectively) in the intervention group, which was statistically significant $(\mathrm{p}<0.01)$. The repeated ANOVA measures for the control group from baseline to 6 months follow up did not show a statistical difference between the time points $\left(\mathrm{F}_{(1.906,343.144)}=0.950 \mathrm{p}=0.384\right)$, and indicate no statistically significance was seen (Table 2). Therefore, we can conclude that a mobile PHDP text message was effective in improving the attitudes of young people PLWHA towards ART. 
Table 1. Test of within-Subject Effects for Attitude towards ART in Intervention Group

\begin{tabular}{|l|l|l|l|l|l|}
\hline \multicolumn{2}{|l|}{ Variable } & df & Mean Square & F & p-value $^{\mathbf{a}}$ \\
\hline Attitude towards ART & Greenhouse-Geisser & 1.162 & 356.498 & 155.479 & .000 \\
\hline $\begin{array}{l}\text { Error (Attitude towards } \\
\text { ART) }\end{array}$ & Greenhouse-Geisser & 210.381 & 2.293 & & \\
\hline
\end{tabular}

${ }^{\mathrm{a}} \mathrm{p}$-value obtained by repeated measures ANOVA

*Significant at $\mathrm{p}<0.05$

Table 2. Test of within-Subject Effects for Attitude towards ART in Control Group

\begin{tabular}{|l|l|l|l|l|l|}
\hline \multicolumn{2}{|l|}{ Variable } & df & Mean Square & F & p-value $^{\text {a }}$ \\
\hline Attitude towards ART & Greenhouse-Geisser & 1.906 & .330 & .950 & .384 \\
\hline $\begin{array}{l}\text { Error (Attitude towards } \\
\text { ART) }\end{array}$ & Greenhouse-Geisser & 343.144 & .348 & & \\
\hline
\end{tabular}

ap-value obtained by repeated measures ANOVA

*Significant at $\mathrm{p}<0.05$.

Post hoc tests using the Bonferroni for repeated measures analysis showed a significant increase in attitude scores in respondents

between baseline and 2 months, baseline and 4 months, and baseline and 6 months in intervention group (Table 3).

Table 3. A Repeated Measures ANOVA Analysis on the Effectiveness of the Mobile PHDP Text Messages on the Attitude towards ART of Young PLWHA in Intervention Group

\begin{tabular}{|l|l|l|l|l|}
\hline Time & Time & Attitude Mean Difference & Std. Error & p-value $^{\mathbf{a}}$ \\
\hline \multirow{3}{*}{ Baseline } & 2 months & $-.192^{*}$ & .047 & .000 \\
\cline { 2 - 5 } & 4 months & $-1.599^{*}$ & .122 & .000 \\
\cline { 2 - 5 } & 6 months & $-1.599^{*}$ & .122 & .000 \\
\hline \multirow{2}{*}{ 2 months } & 4 months & $-1.407^{*}$ & .116 & .000 \\
\cline { 2 - 5 } & 6 months & $-1.407^{*}$ & .116 & .000 \\
\hline \multirow{2}{*}{ 4 months } & 6 months & .000 & .000 &. \\
\hline
\end{tabular}

ap-value obtained by repeated measures ANOVA

Based on estimated marginal means

*. The mean difference is significant at the 0.05 level.

a. Adjustment for multiple comparisons: Bonferroni

Post hoc tests using the Bonferroni for respondents between baseline and 2 months, repeated measures analysis did not show a baseline and 4 months, and baseline and 6 significant increase in attitude scores in months in the control group (Table 4).

Table 4. A Repeated Measures ANOVA Analysis on the Effectiveness of the mobile PHDP Text Messages on the Attitude towards ART of young PLWHA in Control Group

\begin{tabular}{|l|l|l|l|l|}
\hline Time & Time & Attitude Mean Difference & Std. Error & p-value $^{\mathbf{a}}$ \\
\hline \multirow{3}{*}{ Baseline } & 2 months & $-.050^{*}$ & .048 & 1.000 \\
\cline { 2 - 5 } & 4 months & $.033^{*}$ & .070 & 1.000 \\
\cline { 2 - 5 } & 6 months & $-.006^{*}$ & .050 & 1.000 \\
\hline \multirow{2}{*}{ 2 months } & 4 months & $.083^{*}$ & .044 & .376 \\
\cline { 2 - 5 } & 6 months & $.044^{*}$ & .020 & .193 \\
\hline \multirow{2}{*}{ 4 months } & 6 months & $-.039^{*}$ & .050 & 1.000 \\
\hline
\end{tabular}

${ }^{\mathrm{a}} \mathrm{p}$-value obtained by repeated measures ANOVA

Based on estimated marginal means

*. The mean difference is significant at the 0.05 level.

a. Adjustment for multiple comparisons: Bonferroni 


\section{Discussion}

The participants recruited for the study were young adults between the ages of 18 and 30 years. The mean age is like that reported in a study by [36]. The findings of this study show that majority of the participants were females. This indicates that there were more females than men in the ART clinics from which the young people were recruited. Similarly [37], in a study across 12 facilities in Nigeria, reported that were more females than men. There have been reports from around the world of the gender imbalance in the prevalence of HIV/AIDS. Females are reportedly disadvantaged compared to their male counterparts, and evidence from UNAIDS and World Health Organization shows that women are more vulnerable to the virus. In contrast to this [20] reported more men attendee in Malaysia. "The results could be due to the health seeking behaviour of women, and the cultural diversity in which women were mostly housewives and may unknowingly have to acquire the virus from their husbands without confirmation yet. [38] reported similar results to those in this present study". They confirmed that more HIV cases were seen in women and it could be attributed to heterosexual intercourse. In contrast, India records a higher prevalence among men compared to women [39].

\section{Attitude of PLWHA}

Majority of the participants in this study had a positive attitude towards HIV infection. Though they displayed positive disposition towards their condition, a close look at the items indicates that some of them still ranked poorly. Quite a few did not have confidence in their healthcare provider's recommendations about their medications. This lack of confidence could lead to loss of trust in the healthcare system and the antiretroviral therapy. As reported by [40], PLWHA usually seek assistance in making very complex decisions regarding their illness from their physicians. They may seek help occasionally and rather consult friends and family, instead of discussing with healthcare providers. Participants in this study who lack social support may find it difficult to adhere to medications or practice prevention because they may make decisions without guidance. Only about a two-thirds of the young adults reported to have positive support by people who are important to them. Studies have shown a positive association between overall improved health outcomes and social support for PLWHA [41, 42].

More than a quarter of the young adults stated that they were worried the medications they were given may hurt their health. This notion could have been developed due to inadequate knowledge of the effectiveness and role of ART for their conditions. The results show that the young adults were not quite knowledgeable about the importance of the therapy, hence the negative attitude. Few were worried about the development of side effects due to the medications they used. About half of the participants reported that they often found it difficult to take their medications and use a condom for sexual intercourse when they consume alcohol. Previous studies have established the relationship between unprotected sexual intercourse and consumption of alcohol among people who are infected with HIV [43, 44].

\section{Effectiveness of Mobile PHDP Text Messages on the Attitudinal Disposition of Young PLWHA}

Patients' beliefs regarding HIV/AIDS can facilitate or hinder their treatments. Patients' poor understanding of HIV and the effects of ART has been associated with a higher likelihood of non-adherence [45]. Patients may drop out of therapy and care and this will increase the risk behaviours and transmission potential of the virus. The mobile PHDP intervention effected a change in the attitudinal disposition of the HIV-infected young people in Yola, Adamawa. The observed mean difference between baseline and 6-month follows up period as measured by the repeated measure analysis was statistically significant.

In a study by [9], the results confirm the important potential of negative attitudes as barriers to the progression of HIV treatment among patients. Patients' loss of trust in care provider and the belief that they do not require to take their drugs when they are feeling healthy can severely compromise their immunity. Few of the participants reported concerns for the efficacy and side effects of the ART medications. The concerns the young adults have could be a product of inadequate knowledge of ART. This finding suggests that health provider engagement and counselling can be effective in 
reducing the negative attitudes towards ART and improve preventive behaviours [46, 47].

\section{Limitations}

With the questionnaire as a tool of data collection, responses are dependent on truthfulness of respondents.

\section{Conclusion}

The study shows that mobile positive health and dignity prevention text messages can improve the attitude of young PLWHA towards ART in Nigeria. The HIV-infected patients who received the intervention were more likely to practice prevention of HIV transmission than patients who received the standard care alone. The overall findings of this study suggest that a comprehensive integration of ART and prevention programs may help to improve attitude towards ART thus, reduce HIV transmission in Africa and support continued ART expansion. Although attention and resources have been focused on patients who are registered in ART clinics already, there is still a vast majority of people in need of ART in sub-

\section{References}

[1] UNAIDS. UNAIDS. [Online].; 2017 [cited 2017 November. Available from: http://www.unaids.org/en/resources/documents/2017 /UNAIDS_FactSheet.

[2] UNAIDS. UNAIDS. [Online].; 2017 [cited 2017 November. Available from: http://aidsinfo.unaids.org.

[3] Idele P, Gillespie A, Porth T, Suzuki C, Mahy M, Kasedde S, et al. Epidemiology of HIV and AIDS Among Adolescents: Current Status, Inequities, and Data Gaps. J Acquir Immune Defic Syndr. 2014; 66(2): p. 144-153.

[4] ADSACA. Adamawa State Agency for the Control of HIV/AIDS: 2015 Annual Report. Yola:; 2016.

[5] Bernard EJ. Positive Health, Dignity and Prevention. Technical Consultation Report, 27-28 April 2009, Hammamet, Tunisia. Amsterdam:; 2009. [6] UNAIDS. Consultation on concurrent sexual partnerships, Nairobi, Kenya: Recommendations. Geneva:; 2009.

[7] NACA. The mid-term review of the Botswana National Strategic Framework for HIV/AIDS 20032009: On the road to Vision 2016. Gaborone:; 2007.
Saharan Africa who have never tested for HIV or registered for ART.

Overall, the results of this study show that though the mobile phone PHDP intervention was effective, larger multi-centre studies are required in identifying the cost-effectiveness of the strategy in improving attitude towards treatment and preventive behaviours among the HIVinfected youth and ART population in Nigeria and Sub-Saharan Africa at large. Though the studies which have utilized the mobile technology in HIV control and transmission in Nigeria are few, there has been evidence of improved clinical outcomes and preventive behaviours. Findings suggest intervention studies that will counteract the negative attitudes exhibited by the young people.

\section{Acknowledgments}

We thank all the respondents who took part in this study and Adamawa State Ministry of Health. We would also like to acknowledge Dr. Arup Kumar Chakrabartty for the support and guidance during the period of this study.

[8] Uzochukwu B, Onwujekwe O, Onoka A, Okoli C, Uguru N, Chukwuogo O. Determinants of nonadherence to subsidized anti-retroviral treatment in southeast Nigeria. Health Policy Plan. 2009; 24(3): p. 189-96. doi: 10.1093/heapol/czp006.

[9] Culbert G, Bazazi A, Waluyo A, Murni A, Muchransyah A, Iriyanti M, et al. The Influence of Medication Attitudes on Utilization of Antiretroviral Therapy (ART) in Indonesian Prisons. AIDS and Behavior. 2015; 20(5): p. 1026-1038. doi:10.1007/s10461- 015-1198-4.

[10] Fetzer B, Mupenda B, Lusiama J, Kitetele F, Golin C, Behets F. Barriers to and facilitators of adherence to pediatric antiretroviral therapy in a subSaharan setting: insights from a qualitative study. AIDS patient care and STDs. 2011; 25(10): p. 61121.

[11] Rudy B, Murphy D, Harris D, Muenz L, Ellen J. Patient-related risks for nonadherence to antiretroviral therapy among HIV-infected youth in the United States: a study of prevalence and interactions. AIDS patient care and STDs. 2009; 23(3): p. 185-94.

[12] Barclay T, Hinkin C, Castellon S, al. e. Ageassociated predictors of medication adherence in HIV-positive adults: health beliefs, self-efficacy, and 
neurocognitive status. Health psychology : official journal of the Division of Health Psychology, American Psychological Association. 2007; 26(1): p. 40-9.

[13] Murphy D, Wilson C, Durako S, Muenz L, Belzer M. Antiretroviral medication adherence among the REACH HIV-infected adolescent cohort in the USA. AIDS care. 2001; 13(1): p. 27-40.

[14]Belzer M, Fuchs D, Luftman G, Tucker D. Antiretroviral adherence issues among HIVpositive adolescents and young adults. The Journal of adolescent health: official publication of the Society for Adolescent Medicine. 1999; 25(5): p. 316-9.

[15] Kunutsor S, Walley J, Katabira E, Muchuro S, Balidawa H, Namagala E, et al. Using mobile phones to improve clinic attendance amongst an antiretroviral treatment cohort in rural Uganda: a cross-sectional and prospective study. AIDS Behav. 2010; 14(6): p. 1347-52. doi: 10.1007/s10461-0109780-2.

[16] Maduka O, Tobin-West C. Adherence counseling and reminder text messages improve uptake of antiretroviral therapy in a tertiary hospital in Nigeria. Niger J Clin Pract. 2013; 16(3): p. 302-8. doi: 10.4103/1119-3077.113451.

[17] Alfa MA, Zezi AU, Gyang SS, Yusuf H, Aliyu IM. Effect of Counselling and Reminder Text Messages Follow-Up on Adherence to Antiretroviral Therapy in Hajiya Gambo Sawaba General Hospital, Zaria, Nigeria. Journal of Applied Pharmaceutical Science. 2016; 6(09): p. 174-178. DOI: 10.7324/JAPS.2016.60926.

[18] Horvath T, Azman H, Kennedy G, Rutherford G. Mobile phone text messaging for promoting adherence to antiretroviral therapy in patients with HIV infection. Cochrane Database Syst Rev. 2012; 3(Cd009756).

[19] Ambia J, Mandala J. A systematic review of interventions to improve prevention of mother-tochild HIV transmission service delivery and promote retention. J Int AIDS Soc. 2016; 19(1): p. 20309.

[20] Abdulrahman S, Rampal L, Ibrahim F, Radhakrishnan A, Kadir SH, Othman N. Mobile phone reminders and peer counseling improve adherence and treatment outcomes of patients on ART in Malasia: A randomise clinical trial. PLoS ONE. 2017; 12(5): p. e0177698.

[21] US President's Emergency Plan for AIDS Relief. US President's Emergency Plan for AIDS Relief. Monitoring, evaluation, and reporting indicator reference guide. Washington, DC:; 2018.

[22] World Health Organization. HIV strategic information for impact: cascade data use manual to identify gaps in HIV and health services for program improvement. Geneva, Switzerland:; 2019.

[23] Lemeshow S, David WH, Klar J, Lwanga SK. WHO. IRIS: 239. [Online]. IRIS: 239: WHO; 1990. Available from: http://www.who.int/irs/handle/10665/41607.accesse d.

[24] Olowookere SA, Fatiregun AA, Adewole IF. Knowledge and attitudes regarding HIV/AIDS and antiretroviral therapy among patients at a Nigerian treatment clinic. J Infect Dev Ctries. 2012; 6(11): p. 809-816.

[25] WHO/HTM. Chronic HIV care with ART and prevention : Integrated Management of Adolescent and Adult Illness, Integrated Management of Childhood Illness interim guidelines for health workers at health centre or district hospital outpatient clinic. Geneva:; 2007.

[26] da Cunha G, de Araujo T, Lima F, Cavalcante T, Galvão M. Hygiene practices for patients with HIV/AIDS. Rev Gaucha Enferm. 2014; 35(3): p. 137144. DOI: http://dx.doi.org/10.1590/19831447.2014.03.44928.

[27]LOFTYSMS. LOFTYSMS. [Online].; 2018 [cited 2018 February 14. Available from: https://www.loftysms.com/?gclid=CjwKCAiAtorUB RBnEiwAfcp_Ywz2r2xhnVAJ5WRNizUrLvH2ap3 G9Dhkq1CBCahhLQrk_aIkhJmihRoC2wwQAvD_ BwE.

[28] Strunin L, Culbert A, Crane S. First year medical students' attitudes and knowledge about AIDS. AIDS Care. 1989; 1(1): p. 105-10. DOI: 10.1080/09540128908260242.

[29] Li V, Cole B, Zhang S, Chen C. HIV-related knowledge and attitudes among medical students in China. AIDS Care. 1993; 5(3): p. 305-12. DOI: 10.1080/09540129308258613.

[30] Amalraj E, Chandrasekaran N, Solomon S, Sumbandam R. First-year medical students' AIDS knowledge and attitude. Indian J Community Med. 1995; 20: p. 36-40.

[31] Merakou K, Costopoulos C, Marcopoulou J, Kourea-Kremastinou J. Knowledge, attitudes and behaviour after 15 years of HIV/AIDS prevention in schools. Eur J Public Health. 2002; 12(2): p. 90-3.

[32] Stulhofer A, Graham C, Bozicević I, Kufrin K, Ajduković D. HIV/AIDS-Related Knowledge, Attitudes And Sexual Behaviors as Predictors of Condom Use Among Young Adults in Croatia. Int Fam Plan Perspect. 2007; 33(2): p. 58-65.

[33] Qu B, Guo H, Sun G, Zuo T, Zhang Y, Li B. HIV/AIDS Knowledge, Attitudes, and Behaviors of 
Construction Workers in China. Int $\mathbf{J}$ Biomed Sci. 2008; 4(3): p. 192-195.

[34] Ugarte W, Högberg U, Valladares E, Essén B. Assessing knowledge, attitudes, and behaviors related to HIV and AIDS in Nicaragua: A community-level perspective. Sex Reprod Healthc. 2013; 4(1): p. 37-44. doi: 10.1016/j.srhc.2012.11.001.

[35] Vaidya A, Aryal UR, Krettek A. Cardiovascular health knowledge, attitude and practice/behaviour in an urbanising community of Nepal: a populationbased cross-sectional study from Jhaukhel-Duwakot Health Demographic Surveillance Site. BMJ Open. 2013; doi: 10.1136/bmjopen-2013-002976: p. 3(10): 002976

[36] Beyrer C, Baral SD, Griensven F, Goodreau SM, Chariyalertsak S, Wirtz AL, et al. Global Epidemiology of HIV Infection in Men Who Have Sex with Men. The Lancet. 2012; 380(9839): p. 367377 doi: 10.1016/S0140-6736(12)60821-6.

[37] Anoje C, Agu KA, Oladele EA, Badru T, Adedokun O, Oqua D, et al. Adherence to On-Time ART Drug Pick-Up and Its Association with CD4 Changes and Clinical Outcomes Amongst HIV Infected Adults on First-Line Antiretroviral Therapy in Nigerian Hospitals. AIDS Behav. 2017; 21(2): p. 386-392. doi: 10.1007/s10461-016-1473-z.

[38] Saddki N, Sulaiman Z, Abdullah S, Zakaria N, Mohamad N, Ab Razak A, et al. HIV-related knowledge among people living with HIV/AIDS in Kelantan, Malaysia. Journal of HIV/AIDS \& Social Services. 2016; 15(2): p. 216-233 DOI: 10.1080/15381501.2013.816648.

[39] Ramchandani SR,MSH, Saple DG, Vaidya SB, Pandey VP, Vadrevu R, Gupta A. Knowledge, Attitudes, And Practices of Antiretroviral Therapy among HIV-Infected Adults Attending Private And Public Clinics in India. AIDS Patient Care STDS. 2007; 21(2): p. 129-42 doi:10.1089/apc.2006.0045. [40] Guenter D, Gillett J, Cain R, Pawluch D, Travers R. What Do People Living With HIV/AIDS Expect From Their Physicians? Professional Expertise and the Doctor- Patient Relationship. Journal of the International Association of Physicians in AIDS Care. 2010; 9(6): p. 341-345. doi: $10.1177 / 1545109710370486$.

[41] Shippy R, Karpiak S. The aging HIV/AIDS population: Fragile social networks. Aging \& Mental Health. 2005; 9(3): p. 246-254. DOI: $10.1080 / 13607860412331336850$.

[42] Kingori C, Haile Z, Ngatia P. Depression symptoms, social support and overall health among HIV-positive individuals in Kenya. International Journal of STD \& AIDS. 2015; 26(3): p. 65-72. doi: 10.1177/0956462414531933. Epub 2014 Apr 22.

[43] Ehrenstein V, Horton N, Samet J. Inconsistent condom use among HIVinfected patients with alcohol problems. Drug and Alcohol Dependence. 2004; 73(2): p. 159-166. DOI: 10.1016/j.drugalcdep.2003.10.011.

[44] Brown J, DiClemente R, Sales J, Rose E, Gause $\mathrm{N}$, Safonova $\mathrm{P}$, et al. Alcohol Use, Partner Characteristics, and Condom Use Among HIVInfected Russian Women: An Event-Level Study. Journal of Studies on Alcohol and Drugs. 2016; 77(6): p. 968-973. DOI: 10.15288/jsad.2016.77.968. [45] Langebeek N, Gisolf E, Reiss P, Vervoort S, Hafsteinsdóttir T, Richter C, et al. Predictors and correlates of adherence to combination antiretroviral therapy (ART) for chronic HIV infection: a metaanalysis. BMC Med. 2014; 12(142): p. doi: 10.1186/PREACCEPT-1453408941291432.

[46] Unge C, Johansson A, Zachariah R, Some D, Van Engelgem I, Ekstrom A. Reasons for unsatisfactory acceptance of antiretroviral treatment in the urban Kibera slum, Kenya. AIDS Care. 2008; 20(2): p. 146-9. doi: 10.1080/09540120701513677. [47] Wasti S, van Teijlingen E, Simkhada P, Randall J, Baxter S, Kirkpatrick P, et al. Factors influencing adherence to antiretroviral treatment in Asian developing countries: a systematic review. Trop Med Int Health. 2012; 17(1): p. 71-81. doi: 10.1111/j.1365-3156.2011.02888.x. 